\title{
The hSSB1 orthologue Obfc2b is essential for skeletogenesis but dispensable for the DNA damage response in vivo
}

\author{
Niklas Feldhahn ${ }^{1, *}$, Elisabetta Ferretti², \\ Davide F Robbiani ${ }^{1}$, Elsa Callen ${ }^{3}$, \\ Stephanie Deroubaix ${ }^{1}$, Licia Selleri², \\ Andre Nussenzweig ${ }^{3}$ and \\ Michel C Nussenzweig ${ }^{1,4}$
}

${ }^{1}$ Laboratory of Molecular Immunology, Rockefeller University, New York, NY, USA, ${ }^{2}$ Department of Cell and Developmental Biology, Weill Medical College of Cornell University, New York, NY, USA, ${ }^{3}$ Laboratory of Genome Integrity, National Cancer Institute National Institutes of Health, Bethesda, MD, USA and ${ }^{4}$ Howard Hughes Medical Institute, Rockefeller University, New York, NY, USA

Human single-stranded DNA-binding protein 1 (hSSB1), encoded by $O B F C 2 B$, was recently characterized as an essential factor for the initiation of DNA damage checkpoints and the maintenance of genomic stability. Here, we report that loss of $O b f c 2 b$ in mice results in perinatal lethality characterized by growth delay and skeletal abnormalities. These abnormalities are associated with accumulation of $\gamma \mathrm{H} 2 \mathrm{ax}$, apoptosis and defective pre-cartilage condensation, which is essential for normal bone formation. However, deficiency of $O b f c 2 b$ does not affect the initiation of DNA damage checkpoints, Atm activation, or the maintenance of genomic stability in B lymphocytes and primary fibroblasts. Loss of $O b f c 2 b$ results in increased expression of its homologue $O b f c 2 a$ (hSSB2). In contrast to $O b f c 2 b$ deficiency, depletion of Obfc2a in fibroblasts results in impaired proliferation, accumulation of $\gamma \mathrm{H} 2 \mathrm{ax}$ and increased genomic instability. Thus, the hSSB1 orthologue $O b f c 2 b$ has a unique function during embryogenesis limited to cell types that contribute to bone formation. While being dispensable in most other cell lineages, its absence leads to a compensatory increase in Obfc2a protein, a homologue required for the maintenance of genomic integrity. The EMBO Journal (2012) 31, 4045-4056. doi:10.1038/ emboj.2012.247; Published online 31 August 2012 Subject Categories: genome stability \& dynamics; development Keywords: apoptosis; DNA damage response; hSSB1; Obfc2b; skeletogenesis

\section{Introduction}

Nuclear DNA is normally double-stranded, but single-stranded DNA (ssDNA) is exposed during DNA replication, meiosis, transcription, and DNA double-strand break (DSB) repair.

\footnotetext{
*Corresponding author. Laboratory of Molecular Immunology, The Rockefeller University, 1230 York Avenue, Box 220, New York, NY 10065, USA. Tel.: + 1212327 8098; Fax: + 1212327 8370; E-mail: nfeldhahn@rockefeller.edu
}

Received: 30 May 2012; accepted: 9 August 2012; published online: 31 August 2012
ssDNA, which is an obligate intermediate in these reactions, is more vulnerable to chemical and physical damage than double-stranded DNA (dsDNA). The increased vulnerability of ssDNA is alleviated in part by ssDNA-binding proteins that stabilize, protect and facilitate the repair of damaged ssDNA (reviewed by Mendez and Stillman, 2003). Underlining their importance, loss of function of the ssDNA-binding protein replication protein A (Rpa1) results in embryonic lethality in mice (Wang et al, 2005). Even heterozygous Rpal mutant mice show an increase in genomic instability and develop lymphoid tumours (Wang et al, 2005).

Two additional ssDNA-binding proteins, hSSB1 (OBFC2B, NABP2 or SOSS-B1) and hSSB2 (OBFC2A, NABP1 or SOSS$\mathrm{B} 2$ ), are also thought to be essential for recognition and repair of DNA damage (Richard et al, 2008, 2011a, b; Huang et al, 2009; Li et al, 2009; Zhang et al, 2009). Similarly to RPA1, hSSB1 and hSSB2 form heterotrimeric complexes that are required for their recruitment to DSBs (Huang et al, 2009; Li et al, 2009; Skaar et al, 2009; Zhang et al, 2009). RNA interference (RNAi) experiments indicated that hSSB1 is essential to induce phosphorylation of ataxia telangiectasia mutated (ATM) kinase and its downstream targets in response to DNA damage. Moreover knockdown of hSSB1 is reported to abrogate irradiation-induced G1/S and G2/M cell-cycle arrest and result in genomic instability (Richard et al, 2008; Huang et al, 2009; Li et al, 2009; Zhang et al, 2009). In addition to repair and checkpoint functions, it has been proposed that hSSB1 is also required to produce ssDNA at sites of DSBs and that it does so by recruiting the MRN (MRE11/RAD50/NBS1) complex and the CtBP-interacting protein (CTIP) endonuclease (Richard et al, 2011a,b). However, the role of hSSB1 in DNA repair has only been tested in RNAi knockdown experiments in cell lines.

To study the role of the ssDNA-binding protein hSSB1 in vivo, we produced conditional knockout mice for the $h S S B 1$ orthologue $O b f c 2 b$. We find that $O b f c 2 b$ exhibits an essential, unique and cell type-specific role during embryogenesis. Germline deletion of $O b f c 2 b$ results in increased replication-associated DNA damage and apoptosis in cell types that are essential for skeletal development and, hence, in severe skeletal defects and perinatal lethality. Furthermore, loss of $O b f_{c} 2 b$ results in a compensatory increase of its homologue Obfc2a (orthologue to hSSB2). Unexpectedly, these ssDNA-binding proteins are not required to initiate the DNA damage response to irradiation, but play an important tissue-specific role in the suppression of replication-associated DNA damage.

\section{Results}

\section{Germline deletion of Obfc2b results in embryonic lethality}

Human ssDNA-binding protein 1 (hSSB1 or SOSS-B1) is encoded by the $O B F C 2 B$ gene (oligonucleotide/oligosacchar- 
A

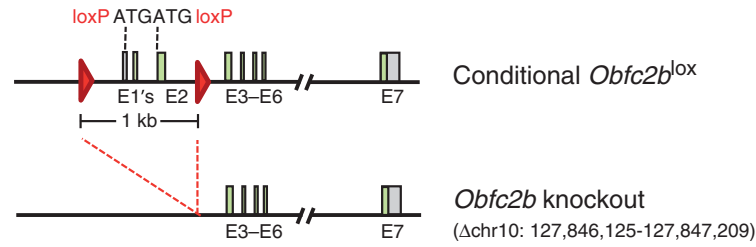

B

\begin{tabular}{l|ll|ll|ll} 
& \multicolumn{2}{|c|}{ Obfc2 $b^{+/+}$} & \multicolumn{2}{|c|}{ Obfc2 $b^{+/-}$} & \multicolumn{2}{|c}{ Obfc2b } \\
\hline E13.5 & $7 / 38$ & $(18 \%)$ & $23 / 38$ & $(61 \%)$ & $8 / 38$ & $(21 \%)$ \\
E18.5 & $9 / 43$ & $(21 \%)$ & $24 / 43$ & $(56 \%)$ & $10 / 43$ & $(23 \%)$ \\
Liveborn & $47 / 129$ & $(36 \%)$ & $82 / 129$ & $(64 \%)$ & $0 / 129$ & $(0 \%)$
\end{tabular}

C

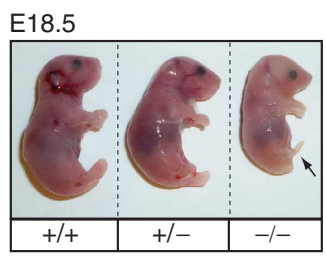

PO

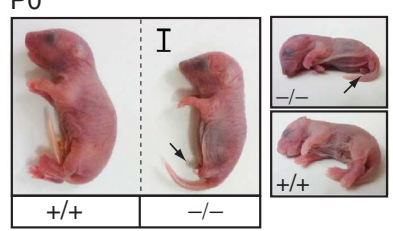

D

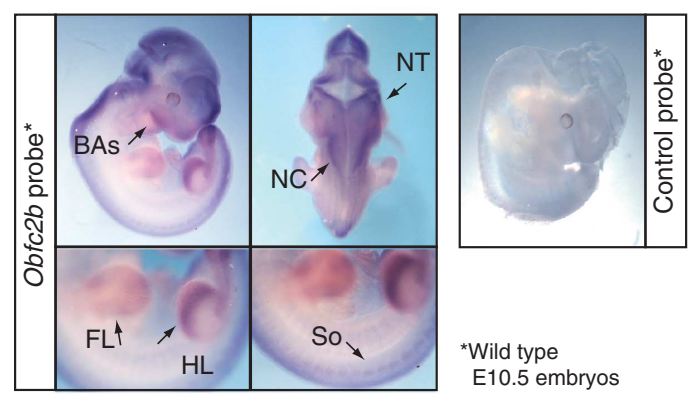

Figure 1 Loss of $O b f_{c} 2 b$ results in embryonic lethality and developmental abnormalities. (A) Design of the conditional $O b f c 2 b$ allele. Schematic of the murine $O b f c 2 b^{\text {lox }}$ allele with integrated loxP sites before (upper panel), and after Cre-mediated disruption (lower panel) is shown. (B) $O b f c 2 b$ deficiency results in embryonic lethality. Table of genotypes observed from $O b f c 2 b^{+/-}$intercrosses are shown. (C) $O b f c 2 b$ deficiency results in developmental abnormalities. Appearance of embryos at days E18.5 (left) and P0 (right) is shown. Bar marks size difference and arrows mark developmental abnormalities of the hindlimbs. (D) Obfc2b mRNA analysis in wild-type embryos at day E10.5 by in situ hybridization. Arrows indicate specific staining at the branchial arches (BAs), neural crest (NC), neural tube (NT), forelimbs (FL) and hindlimbs (HL) and somites (So) using the anti-sense probe. An $O b f c 2 b$ sense probe was used as control (right).

ide-binding fold containing 2B; Supplementary Figure 1A). To conditionally delete $h S S B 1$, in mice, we introduced loxP sites flanking exons 1 and 2 of $O b f c 2 b$ in mouse embryonic stem (ES) cells $\left(O b f c 2 b^{\text {lox }}\right.$; Figure $1 \mathrm{~A}$ and Supplementary Figure 1B). To generate mice carrying an $O b f c 2 b$ knockout allele, $O b f c 2 b^{\text {lox }}$ mice were bred with mice expressing the EIIA $^{\text {Cre }}$ transgene (Lakso et al, 1996; Supplementary Figure 1B and $\mathrm{C})$. Cre-mediated loss of Obfc2b protein was confirmed by western blotting of $\mathrm{B}$ cells from $\mathrm{CD} 19^{\mathrm{Cre}} ; \mathrm{Obfc} 2 b^{\text {lox } /-}$ mice (Supplementary Figure 1D and see below).

To determine whether $O b f_{c} 2 b$ is essential for mouse development, $\mathrm{Obfc2b^{+/- }}$ mice were interbred. Out of 129 pups analysed at $0-2$ weeks of age, we found no viable $O b f c 2 b^{-1-}$ mice even on the day of delivery (P0) (Figure 1B). However, $O b f c 2 b^{-1-}$ embryos were present at nearly Mendelian ratios as late as at embryonic day 18.5 (E18.5, Figure 1B). At this time, the homozygous mutant embryos appeared to be viable but exhibited significant growth delay, rudimentary hin- dlimbs (HL) and an abnormal skull (Figure 1C). We conclude that loss of $O b f c 2 b$ results in developmental abnormalities during embryogenesis and perinatal death.

To determine whether the developmental abnormalities in

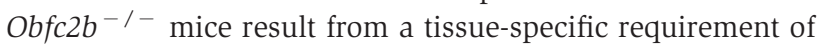
$O b f c 2 b$ function during embryogenesis, we performed in situ hybridization for $O b f c 2 b$ mRNA expression on wild-type E10.5 embryos. $O b f c 2 b$ was expressed in several tissues that contribute to the development of skeletal structures (Figure 1D). These include the limb buds that organize the development of fore- and hindlimbs (FL, HL); the somites (So) which form in part the sclerotome and further the vertebrae and part of the skull; the branchial arches (BAs) that contribute to the development of the mandibles and the palate; and the prospective neural crest ( $\mathrm{NC}$ ) that can give rise to craniofacial mesenchyme and further form craniofacial cartilage and bones. In addition, Obfc2b mRNA expression seemed to be specific for the closing neural tube (NT) and different regions of the head (Figure 1D). We conclude that $\mathrm{Obfc} 2 \mathrm{~b}$ shows a tissue-specific expression pattern during normal embryogenesis.

\section{Obfc2 b $^{-/-}$embryos exhibit severe skeletal defects}

To characterize skeletal defects in more depth, we visualized cartilage and mineralized bone in E18.5 embryos (Figure 2).

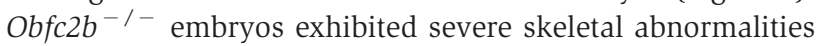
affecting the rib cage, limbs and skull: the rib cage showed a general decrease in size and ossified rib segments were missing or rudimentary (Figure 2A). Since the lower rib cage serves as an anchor for the thoracic diaphragm, it is likely that the perinatal death of $O b f c 2 b^{-/-}$embryos is caused by respiratory failure. Micro-computer tomography (MicroCT) analysis of dead $\mathrm{Obfc}_{2} \mathrm{~b}^{-/-}$newborns (P0) confirmed the presence of a rudimentary rib cage and revealed that the bones were thinner and showed increased porosity (Supplementary Figure 2). Furthermore, the skull had a hypoplastic lower mandible (Figure 2B, left), the tympanic ring of the inner ear was rudimentary and the palate was cleft (Figure 2B, right). In the region of the forelimbs, the spine of the scapula and the deltoid tuberosity of the humerus were missing or rudimentary, respectively (Figure 2C, left). There was variable penetrance of skeletal abnormalities in the hindlimbs, which included missing digits (Figure 2C, right). MicroCT of the femurs revealed a significant decrease in bone volume (Supplementary Figure 2B-D). This pattern of skeletal defects is consistent with the pattern of $O b f c 2 b$ expression in wild-type E10.5 embryos described above (Figure 1D). We conclude that $O b f c 2 b$ deficiency results in multiple skeletal defects during embryogenesis.

\section{Osteoblasts, chondrocytes and osteoblasts in Obfc2b - $^{-1}$ mice}

To determine whether skeletal defects in $O b f c 2 b^{-/-}$mice arise as a consequence of aberrant differentiation or function of bone forming cells, we isolated osteoblasts, chondrocytes and osteoclasts from wild-type and $O b f c 2 b^{-/-}$mice. Osteoblasts were isolated from the calvaria of the skull from E18.5 embryos; chondrocytes were isolated from the sternum of the ribcage. Osteoclasts were generated from bone marrow cells by stimulation with RANK-L and M-CSF for 5 days in culture and osteoclast identity was verified by Tartrate-resistant Acidic Phosphatase (TRAP) staining (Supplementary Figure 3A). 


\section{A}
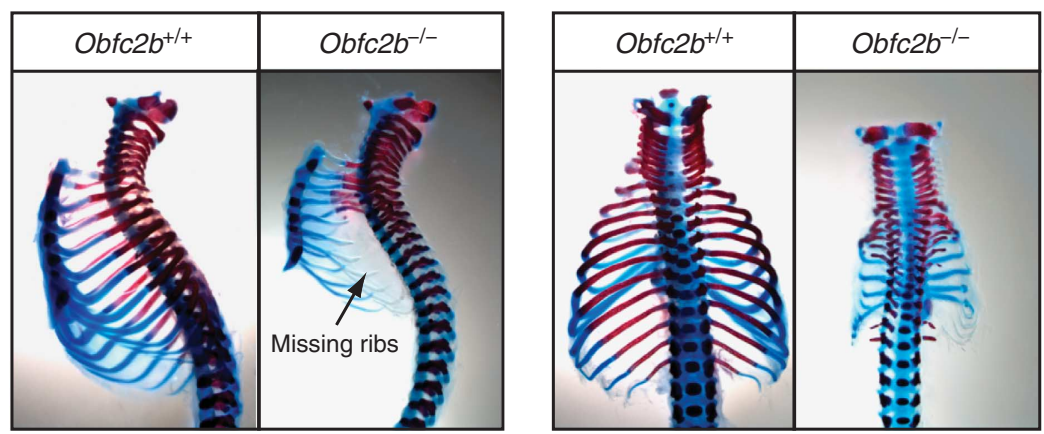

B
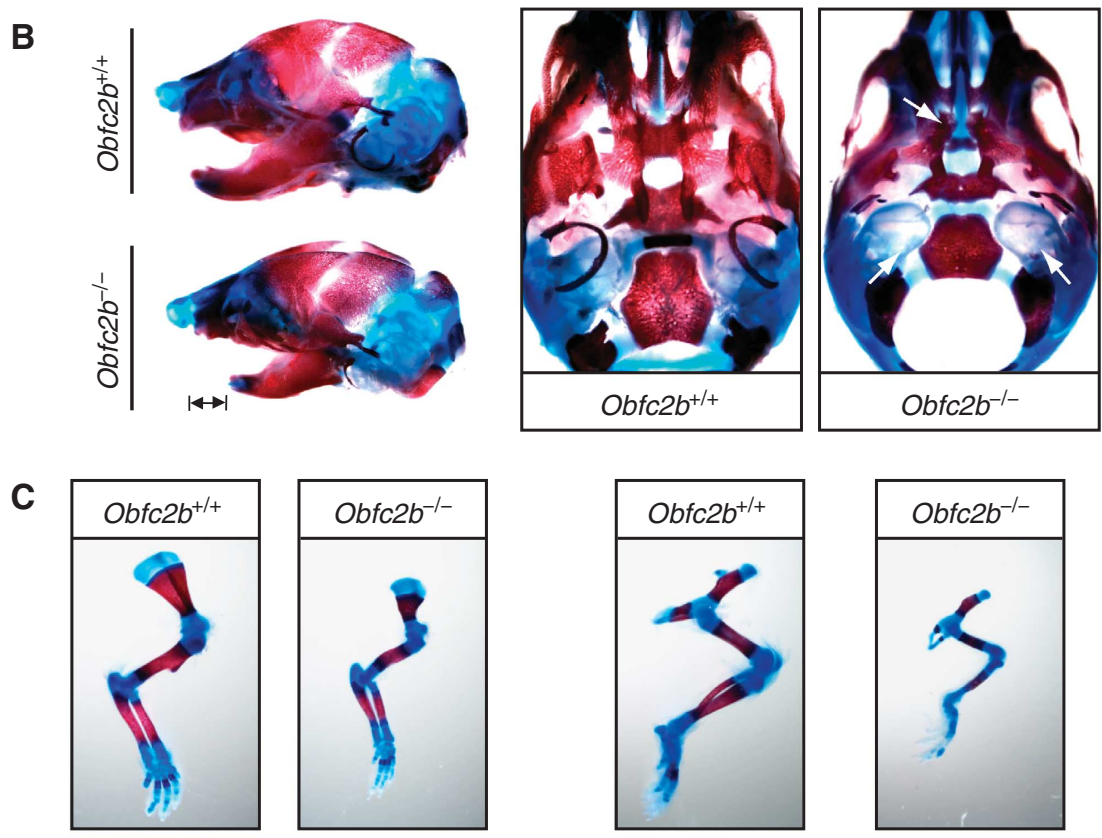

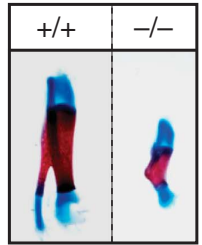

Scapula (forelimb)

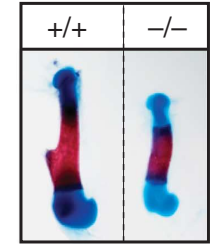

Humerus (forelimb)

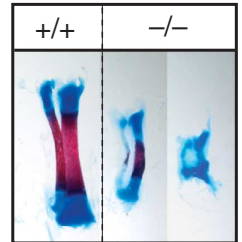

Fibula + tibia (hindlimb)

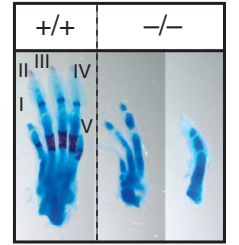

Autopod (hindlimb)

Figure 2 Skeletal abnormalities in $O b f c 2 b^{-/-}$embryos. (A) Rib cage preparations of E18.5 embryos visualized by Alcian blue and Alizarin red staining indicating cartilage (blue) and mineralized/ossified tissue (red). (B) Skull preparations: bars mark size differences in the lower mandible (left) and arrows mark the rudimentary tympanic ring and the cleft palate in skulls from $O b f c 2 b^{-1-}$ embryos (middle and right). (C) Preparations of the forelimbs (left panels) and hindlimbs from wild-type and $O b f c 2 b^{-1-}$ embryos (right panels).

Isolated cells were then subjected to gene expression analysis using gene arrays. Expression of osteoblast-, chondrocyte- and osteoclast-specific genes confirmed the identity of the isolated cell subsets (Supplementary Figure 3B). Comparison of gene arrays from wild-type and $O b f c 2 b^{-1-}$ cells showed that $O b f c 2 b$ was expressed in wild-type but not in $O b f c 2 b^{-1-}$ cells. However, wild-type and $O b f_{c} 2 b^{-/-}$cells were otherwise indistinguishable (Supplementary Figure 3C). We conclude that deficiency of $O b f c 2 b$ does not lead to significant changes in osteoblast, chondrocyte or osteoclast gene expression.

\section{Skeletal defects are associated with increased apoptosis}

Since the human $O b f c 2 b$ orthologue $h S S B 1$ has been implicated in DNA repair and DNA repair deficiencies can result in apoptosis during embryogenesis (Gao et al, 1998), we asked whether the skeletal defects in $\mathrm{Obf} 2 \mathrm{~b}^{-/-}$embryos were associated with increased apoptosis. To detect apoptotic cells, we performed terminal deoxynucleotidyl transferase dUTP nick end labelling (TUNEL) on tissue sections from E10.5, E12.5 and E16.5 embryos. Whereas E10.5 and E16.5 $\mathrm{Obfc} 2 b^{-1-}$ embryos displayed no notable abnormalities (Supplementary Figure $4 \mathrm{~A}$ and B), E12.5 Obfc2 $\mathrm{b}^{-/-}$ embryos showed significantly increased numbers of apoptotic cells in the developing ribs, hindlimb (HL) bud and branchial arches (BAs) (Figure 3A; Supplementary Figure 4C). This pattern of TUNEL staining is consistent with the majority of the described skeletal defects at E18.5 (see Figure 2).

To determine whether the skeletal defects in $O b f c 2 b^{-1-}$ embryos can be rescued by loss of $p 53$, we interbred the two 
A

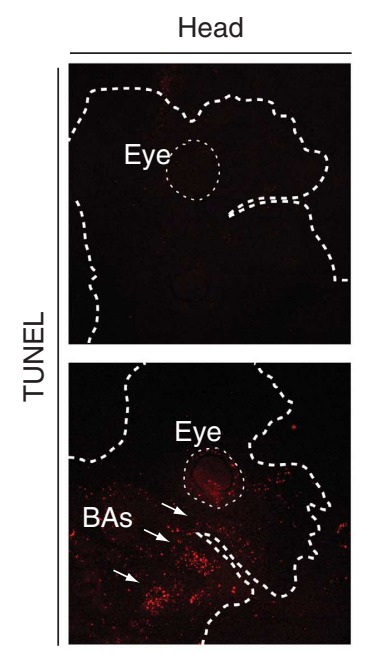

Chest

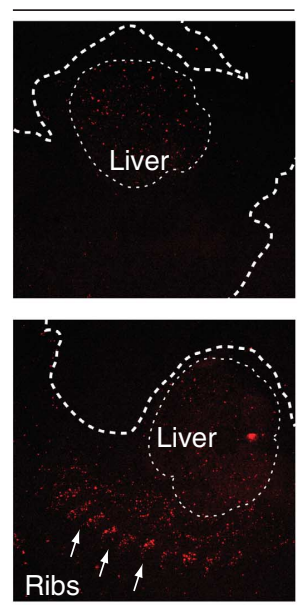

Hindlimb
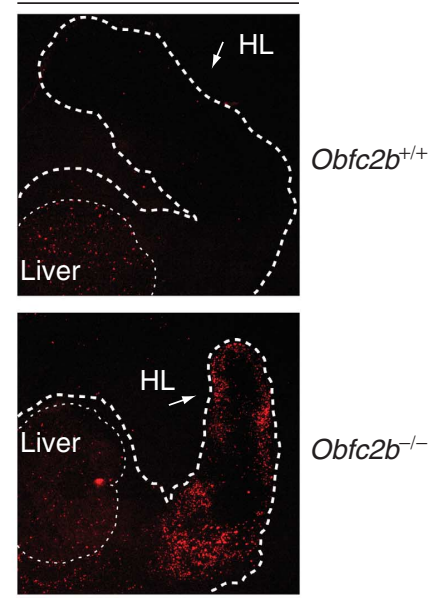

B
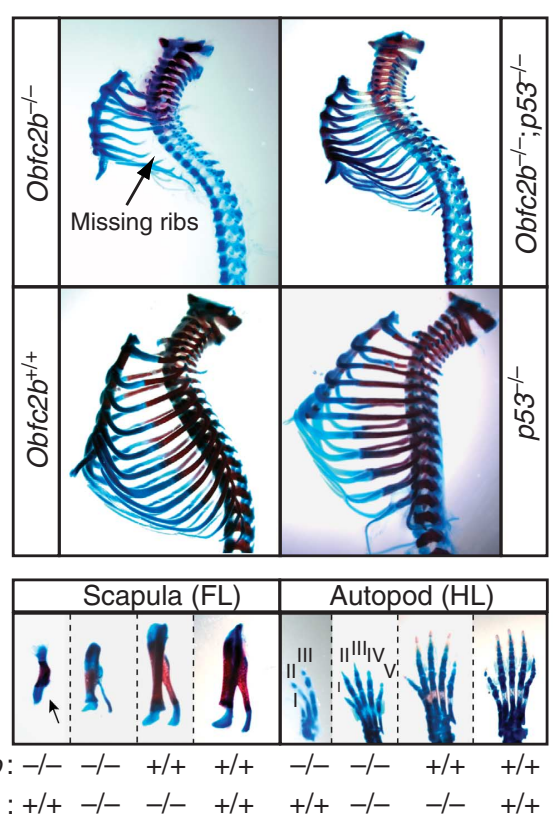

C

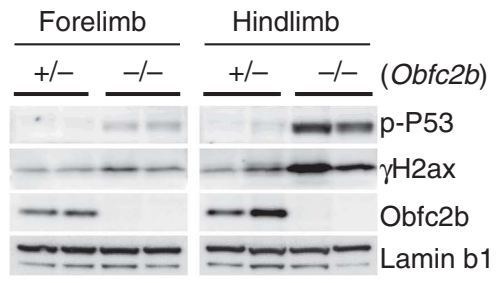

D

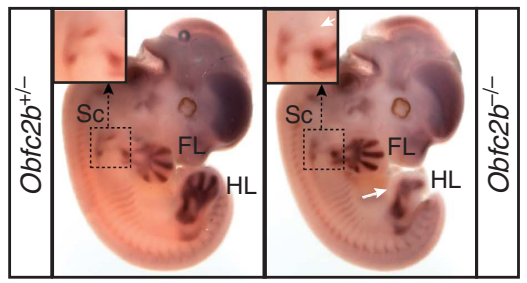

Forelimb (FL)

Hindlimb (HL)

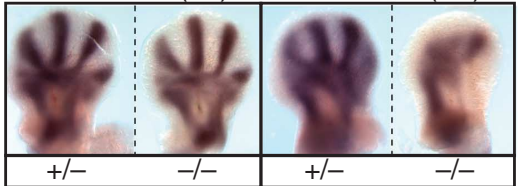

Figure 3 Increased skeletal apoptosis in $O b f c 2 b^{-/-}$embryos. (A) Obfc2b deficiency is associated with increased apoptosis at E12.5. Terminal deoxynucleotidyl transferase dUTP nick end-labelling (TUNEL) staining of representative tissue sections of E12.5 embryos. Arrows indicate regions of developing branchial arches (BAs), developing ribs and developing hindlimbs (HL). (B) P53 loss partially rescues skeletal abnormalities in $O b f c 2 b^{-1-}$ embryos. Alcian blue and Alizarin red stained skeletal preparations from PO Obfc $2 b^{-/-} ; p 53^{+/+}, O b f c 2 b^{-/-}$; $p 53^{-1-}, O b f c 2 b^{+1+} ; p 53^{-1-}$ and $O b f c 2 b^{+1+} ; p 53^{+1+}$ embryos as in Figure 2. Preparations of the rib cage (upper panels), and of the scapula of the forelimb (lower left) and the autopod of the hindlimb (lower right) are shown. (C) Western blot analysis of hind- and forelimbs from E12.5 embryos for phospho-p53 (serine 15), $\gamma \mathrm{H} 2 \mathrm{ax}$, Obfc2b and Lamin b1. (D) In situ hybridization of whole embryos (E12.5) for Sox9 mRNA. Upper panels: images of whole embryos are shown including a magnification of the developing scapula. White arrows indicate aberrant Sox 9 staining at the scapula and at the hindlimb. Lower panels: Sox9 staining of forelimbs (left) and hindlimbs (right).

mutant mouse strains to generate $O b f c 2 b^{-1-} ; p 53^{-1-}$ mice. In contrast to $O b f c 2 b^{-1-}$ newborns that were grossly abnormal and not viable, $O b f c 2 b^{-1-} ; p 53^{-1-}$ mice appeared normal, were viable at birth, and survived up to $24 \mathrm{~h}$. Skeletal preparations from $O b f c 2 b^{-/-} ; p 53^{-/-}$mice at P0 showed partial rescue of the thoracic rib cage phenotype (Figure 3B, up), and of the forelimb and hindlimb defects (Figure 3B, low). However, the defects in the skull including the cleft palate were not ameliorated and likely account for the perinatal lethality of the $O b f_{c} 2 b / p 53$ double knockout pups due to the inability to feed. We conclude that most skeletal defects in $O b f c 2 b^{-1-}$ embryos are associated with increased apoptosis and, accordingly, can be partially rescued by loss of $p 53$.

\section{Skeletal defects are associated with increased genomic instability at E12.5}

To investigate whether increased apoptosis in $O b f c 2 b^{-1-}$ embryos results from increased genomic instability, we analysed forelimbs and hindlimbs from E12.5 embryos for $\gamma \mathrm{H} 2 \mathrm{ax}$ accumulation and p53 phosphorylation by western blotting because both are induced by and serve as markers for DNA damage (Figure $3 \mathrm{C}$ ). We found that hindlimbs from $O b f_{c} 2 b^{-/-}$ 
embryos showed increased $\gamma \mathrm{H} 2 \mathrm{ax}$ accumulation and p53 phosphorylation at serine 15 (Figure 3C). In contrast, there was only a minimal increase of $\gamma \mathrm{H} 2 \mathrm{ax}$ accumulation and $\mathrm{p} 53$ phosphorylation in the forelimbs of $O b f c 2 b^{-/-}$embryos, which show only minor skeletal defects. We conclude that the skeletal defects in the limbs of $O b f c 2 b^{-/-}$embryos are associated with and likely to result from increased genomic instability and apoptosis at E12.5.

\section{Defective pre-cartilage condensation at E12.5 in Obfc2 $b^{-1-}$ embryos}

Pre-cartilage mesenchymal condensation precedes the development of chondrocytes and osteoblasts and is essential for the development of skeletal structures (reviewed in Hall and Miyake, 2000 and Kronenberg, 2003). Apoptosis is likely to antagonize pre-cartilage condensation, because defects in skeletogenesis are often associated with increased apoptosis (Akiyama et al, 2002; Cheung et al, 2005; Shim et al, 2010). Conversely, the transcription factor Sox9, which is specifically expressed during condensation in forelimbs and hindlimbs (Wright et al, 1995), is thought to suppress apoptosis (Akiyama et al, 2002). To analyse if increased apoptosis in $O b f c 2 b^{-/-}$embryos is associated with defective pre-cartilage condensation we performed in situ hybridization for Sox9 on whole embryos at E12.5 (Figure 3D). In agreement with the presence of a minimal skeletal defect in the forelimb of $O b f c 2 b^{-1-}$ embryos, precartilage condensation appeared to be mostly normal in the developing forelimbs of $O b f c 2 b^{-/-}$embryos (Figure 3D, top and lower left). In contrast, the hindlimbs, which show a high degree of apoptosis and skeletal defects, showed defective pre-cartilage condensation, as did the developing scapula in the forelimb (Figure 3D, up and lower right). We conclude that increased genomic instability and apoptosis in $O b f c 2 b^{-1-}$ embryos is associated with defective precartilage mesenchymal condensation.

\section{Obfc2b is dispensable for the DNA damage response in B lymphocytes and MEFs}

Lymphocytes are especially sensitive to defects in the DNA damage response because they undergo programmed DNA damage during $\mathrm{V}(\mathrm{D}) \mathrm{J}$ recombination, and immunoglobulin class-switch recombination (CSR in B cells). As a result, lymphocytes development and function is abnormal in mice or humans that are mutant in any of a number of different factors that contribute to the recognition and repair of DNA damage (reviewed in Rooney et al, 2004; Dudley et al, 2005 and Jankovic et al, 2007). The Obfc2b orthologue $h S S B 1$ has been postulated to be required for the recognition of DNA damage and its repair by the homologous recombination (HR) and non-homologous end-joining (NHEJ) pathways (Richard et al, 2008, 2011a,b). To circumvent embryonic lethality and analyse $O b f c 2 b$ function in B cells, we deleted it specifically by combining the conditional allele with a lineage-specific Cre transgene $\left(C D 19^{\mathrm{Cre}} ; \mathrm{Ob}_{c} 2 b^{\mathrm{lox} /-}\right.$ mice). Despite undetectable levels of Obfc2b protein in $C D 19^{\mathrm{Cre}} ; \mathrm{Obf} c 2 b^{\text {lox/- }} \mathrm{B}$ lymphocytes, B cell development in the bone marrow was indistinguishable from control mice (Figure 4A). Likewise, T cell development was indistinguishable in lethally irradiated mice reconstituted with fetal liver cells from wild-type or $O b f c 2 b^{-/-}$embryos (Figure 4B). Moreover, immunoglobulin CSR in stimulated B cells was unaffected by loss of $O b f c 2 b$ (Figure 4C). Since CSR and $\mathrm{V}(\mathrm{D}) \mathrm{J}$ recombination require efficient recognition of DNA damage and its repair by the NHEJ pathway we conclude that $O b f_{c} 2 b$ is not required for DNA damage sensing or its repair by NHEJ in lymphocytes.

Poly (ADP-ribose) polymerase (PARP) is required for the detection of single-strand DNA breaks. Inhibiting this enzyme with Ku58948 (PARPi) destabilizes the genome by increasing the number of ssDNA breaks, many of which develop into DSBs that are repaired by HR (Bryant et al, 2005; Jackson and Bartek, 2009). Cells defective in HR as well as cells treated with the ATM inhibitor Ku55933 (ATMi) are especially sensitive to PARPi treatment and show reduced proliferation in the presence of PARPi (Bunting et $a l, 2010$ ). To determine whether $O b f c 2 b$ is required for $\mathrm{HR}$, we measured $\mathrm{B}$ cell proliferation in the presence or absence of PARPi (Figure 4D). Proliferation was measured by cell division-associated decrease of cytoplasmic staining with carboxyfluorescein succinimidyl ester (CFSE). Cells delayed in proliferation remain CFSE positive after 4 days. Atm ${ }^{-1-}$ B cells or wild-type B cells treated with the ATM inhibitor Ku55933 (ATMi) were used as positive controls, and showed a significant increase of cells with delayed proliferation upon PARPi treatment (CFSE-positive cells; Figure 4D and Supplementary Figure 5). However, there was no measurable effect upon loss of $O b f c 2 b$. We conclude that $O b f c 2 b$ is not required for DNA repair by HR in proliferating B lymphocytes.

To further test if $O b f_{c} 2 b$ is required for the recognition and repair of DNA damage, we irradiated proliferating B cells and analysed metaphases for unrepaired genomic aberrations by fluorescence in situ hybridization (FISH). We found only a small and statistically insignificant increase in genomic aberrations in metaphases from activated $O b f c 2 b^{-/-}$B cells after ionizing irradiation (IR; Figure 4E). We next analysed the frequency of $c-m y c / I g h$ translocations in proliferating B cells, which are a byproduct of CSR. Defects in recognition and repair of DNA damage typically result in a significant increase in such translocations (Ramiro et al, 2006). The frequency of $c-m y c / I g h$ translocations in proliferating $O b f c 2 b$ deficient B cells was slightly elevated compared to $O b f c 2 b$ proficient cells (Figure 4F). Nevertheless, the translocation frequencies observed fall within the range of what is typically reported for wild-type B cells (Ramiro et al, 2004, 2006). We conclude that the $h S S B 1$ orthologue $O b f c 2 b$ is not required to maintain genomic stability in dividing B lymphocytes.

It has been suggested that $h S S B 1$ is required for activation of the G1/S and the G2/M DNA damage checkpoint upon irradiation (Richard et al, 2008). To determine whether the $h S S B 1$ orthologue $O b f c 2 b$ is required for the initiation of DNA damage checkpoints in vivo, we analysed B cells from $C D 19^{\mathrm{Cre}} ; \mathrm{Obf} c 2 b^{\text {lox/ - }}$ mice for cell-cycle arrest in response to irradiation. Cells entering mitosis undergo histone 3 phosphorylation at serine 10. Accordingly, histone 3 phosphorylation is abrogated in response to G2/M checkpoint activation. As expected, inhibition of Atm kinase activity using Ku55933 (ATMi) resulted in a reduced activation of the $\mathrm{G} 2 / \mathrm{M}$ checkpoint in response to irradiation (Fernandez-Capetillo et al, 2002; Figure 5A). However, there was no measurable effect of $O b f c 2 b$ ablation compared to wild-type cells (Figure 5A; Supplementary Figure 6A). Similarly, loss of $O b f c 2 b$ did not affect the G1/S checkpoint 
A

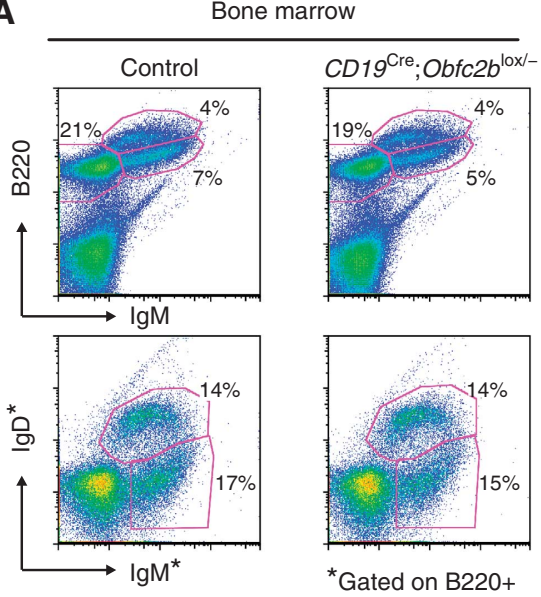

B
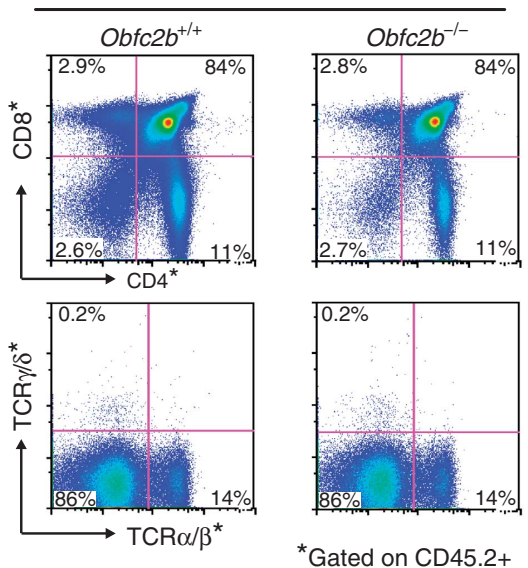

C

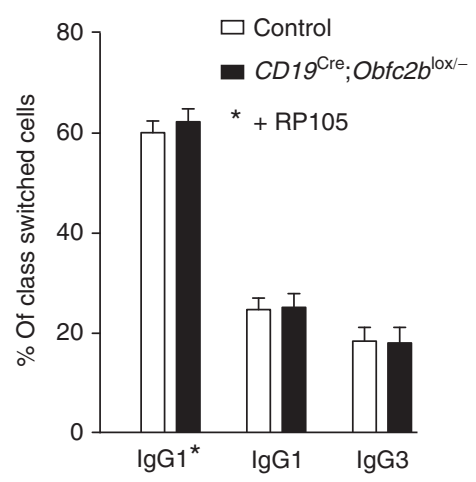

E

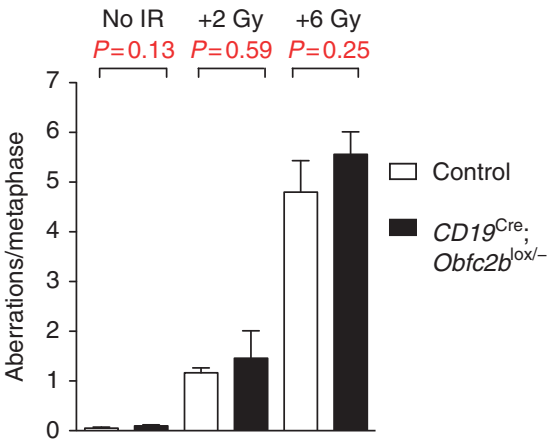

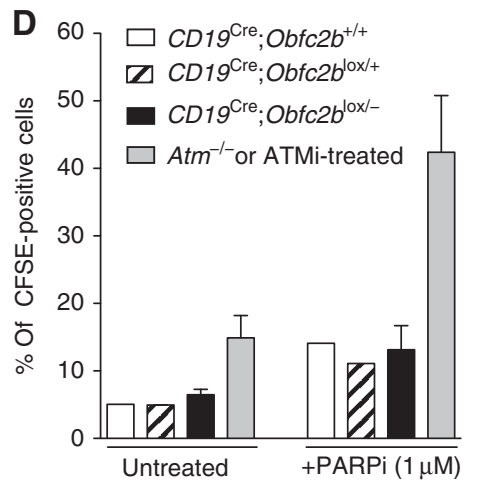

$\mathbf{F}$

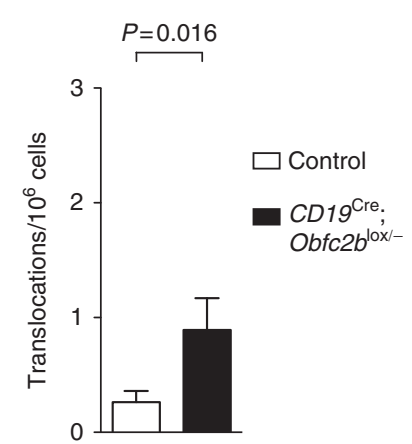

Figure 4 DNA damage response in $O b f c 2 b^{-1-}$ B cells. (A, B) Normal B and T cell development in Obfc2b $b^{-1-}$ mice. (A) Flow cytometry analysis of control $\left(C D 19^{\mathrm{Cre}} ; \mathrm{Obf} c 2 b^{+1+}\right)$ and conditional $O b f c 2 b$ knockout $\left(C D 19^{\mathrm{Cre}} ; \mathrm{Ob} f c 2 b^{\text {lox/- }}\right)$ mice. B cell subsets in the bone marrow were identified using the antibodies indicated. (B) Normal T cell development in $O b f c 2 b^{-1-}$ mice. Thymocytes from lethally irradiated mice reconstituted with fetal liver cells from $O b f c 2 b^{+1+}$ or $O b f c 2 b^{-1-}$ embryos. Analysis was performed $>2$ months after reconstitution. (C) Normal class switch-recombination (CSR) in $O b f c 2 b^{-/-}$B cells. Bar diagram shows mean values of IgG surface expression on conditional Obfc $2 b$ knockout $\left(C D 19^{\mathrm{Cre}} ; \mathrm{Obf} c 2 b^{\mathrm{lox} /-}\right)$ and control B cells $\left(\mathrm{CD} 19^{\mathrm{Cre} /+} ; \mathrm{Obfc} 2 b^{+/+}\right.$and $\left.C D 19^{\mathrm{Cre}} ; \mathrm{Obfc} 2 b^{\text {lox } /+}\right)$ after 4 days of proliferation in vitro, as determined by flow cytometry. IgG1 expression was induced by LPS, IL-4 and RP105 (*) or by LPS and IL-4, IgG3 expression was induced by LPS alone. (D) Normal PARPi sensitivity in $\mathrm{Obfc} 2 \mathrm{~b}^{-/-} \mathrm{B}$ cells. B cells from Obfc2b wild-type mice $\left(\mathrm{CD} 19^{\mathrm{Cre}} ; \mathrm{Obf} c 2 b^{+/+}\right)$, conditional $\mathrm{Obfc} 2 b$ heterozygous mice $\left(C D 19^{\mathrm{Cre}} ; \mathrm{Obfc} 2 b^{\mathrm{lox} /+}\right)$, conditional $\mathrm{Obfc} 2 b$ knockout mice $\left(\mathrm{CD} 19^{\mathrm{Cre}} ; \mathrm{Obfc} 2 b^{\mathrm{lox} /-}\right)$, Atm ${ }^{-/-}$mice or wild-type B cells treated with $2.5 \mu \mathrm{M}$ Ku55933 (ATMi) were stained with carboxyfluorescein succinimidyl ester (CFSE) and analysed by flow cytometry after 4 days in culture with LPS and IL-4. Cells were cultured with or without $1 \mu \mathrm{M}$ Ku58948 (PARPi). Bar diagram shows mean values of five individual experiments. Data observed for Atm ${ }^{-1-}$ B cells and wild-type B cells treated with ATMi have been pooled. For gating of CFSE-positive cells, see Supplementary Figure 5. (E) Normal radiosensivity in $O b f c 2 b^{-/-}$B cells. Metaphase analysis of proliferating B cells from control $\left(C D 19^{\mathrm{Cre}} ; \mathrm{Obf} c 2 b^{+/+}\right.$and $\left.C D 19^{\mathrm{Cre}} ; O b f c 2 b^{\text {lox } /+}\right)$ and conditional Obfc2b knockout mice $\left(C D 19^{\mathrm{Cre}} ; \mathrm{Obfc} 2 b^{\text {lox } /-}\right)$ after irradiation with $6 \mathrm{~Gy}$ ( $20 \mathrm{~h}$ recovery). Bar diagram shows the mean values of eight pairs of mice analysed in five individual experiments. (F) $O b f c 2 b^{-1-} \mathrm{B}$ cells exhibit a slight increase of $c-m y c / I g h$ translocations. PCR analysis of $c$-myc/Igh translocations in B cells from control $\left(C D 19^{\text {Cre }} ; O b f c 2 b^{+/+}\right.$ and $\left.C D 19^{\mathrm{Cre}} ; \mathrm{Obfc2} b^{\mathrm{lox} /+}\right)$ and conditional $\mathrm{Obfc} 2 \mathrm{~b}$ knockout mice $\left(\mathrm{CD} 19^{\mathrm{Cre}} ; \mathrm{Obf} c 2 b^{\mathrm{lox} /-}\right)$. B cells were cultured for 4 days with LPS and IL- 4 previous to analysis. Bar diagram shows the mean of three and four independent experiments for derivative chromosomes 15 and 12 , respectively. Data for both derivative chromosomes has been pooled.

as measured by 5-bromo-2'-deoxyuridine (BrdU) incorporation (Figure 5B; Supplementary Figure 6B): Upon IR, Obfc2bdeficient cells (KO) were indistinguishable from wild-type controls in terms of cell-cycle distribution (Figure 5B). Consistent with the absence of cell-cycle checkpoint defects in response to IR, Western blot analysis showed no altera- 
A
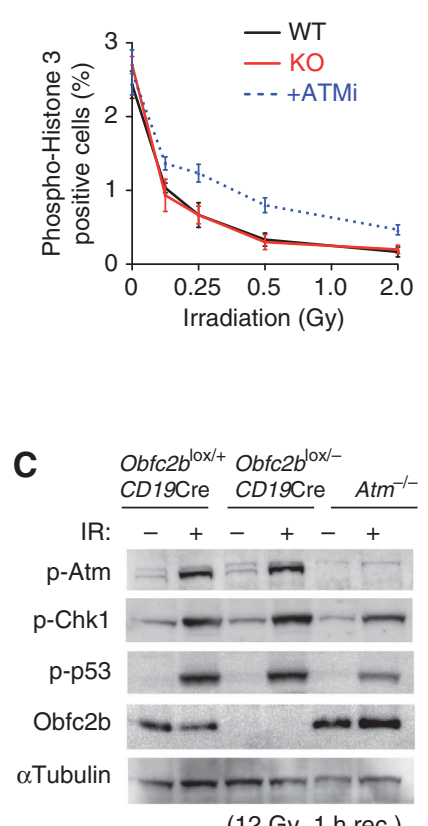

(12 Gy, 1 h rec.)
B
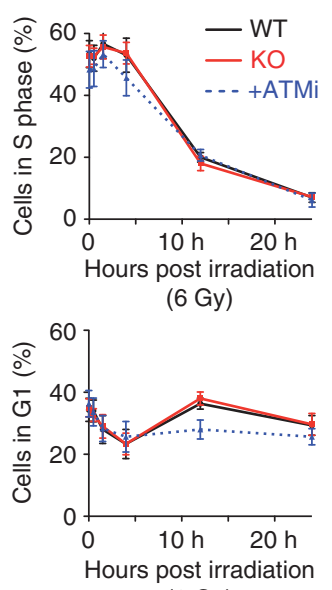

(6 Gy)

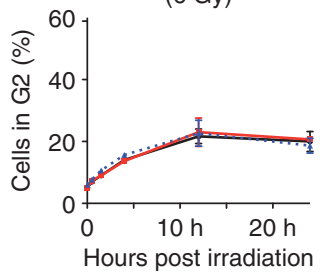

(6 Gy)

CD19 ${ }^{\mathrm{Cre}}(\mathrm{WT}) \quad \mathrm{Obfc} 2 b^{\mathrm{lox} /-} ; C D 19^{\mathrm{Cre}}$ (KO) $C D 19^{\mathrm{Cre}}+\mathrm{ATMi}(+\mathrm{ATMi})$

Figure 5 DNA damage checkpoint analysis. (A) Normal G2/M checkpoint in $O b f c 2 b^{-/-}$B cells. Proliferating B cells from wildtype (WT, $\mathrm{CD} 19^{\mathrm{Cre}} ; \mathrm{Ob} f \mathrm{c} 2 \mathrm{~b}^{+/+}$) and conditional knockout (KO, $C D 19^{\text {Cre }} ; O b f c 2 b^{\text {lox } /-}$ ) mice were analysed for histone 3 (serine 10) phosphorylation before and after irradiation ( $1 \mathrm{~h}$ recovery). As a control, wild-type $\left(\mathrm{CD} 19^{\mathrm{Cre} /+} ; \mathrm{Obfc} 2 b^{+/+}\right)$B cells treated with $2.5 \mu \mathrm{M}$ Ku55933 (ATMi) were analysed. The graph represents the results from three pairs of mice and two independent experiments. (B) Normal G1/S checkpoint in Obfc2b $b^{-/-}$B cells. Proliferating B cells from wild-type (WT, $\mathrm{CD} 19^{\mathrm{Cre}} ; \mathrm{Obfc} 2 \mathrm{~b}^{+/+}$) and conditional knockout (KO, CD19 $9^{\mathrm{Cre}} ; \mathrm{Obfc} 2 b^{\text {lox/--}}$ ) mice were pulsed with BrdU and subjected to cell-cycle analysis. Cells were either mock treated or irradiated with $6 \mathrm{~Gy}$, and allowed to recover for $0.5-24 \mathrm{~h}$. Cells in S phase, G1 and G2 are plotted as individual graphs. Graphs represent the results from three pairs of mice and two independent experiments. (C) Normal IR-induced phosphorylations in $\mathrm{Obfc}_{\mathrm{C}} \mathrm{b}^{-1}$

B cells. Western blot for phosphorylated Atm (serine 1981), Chk1 (serine 317), p53 (serine 15), and for Obfc2b and $\alpha$ Tubulin on lysates from proliferating B cells from $C D 19^{\mathrm{Cre}} ; \mathrm{Obf} c 2 b^{\text {lox } /+}$, $\mathrm{CD} 19^{\mathrm{Cre}} ; \mathrm{Obfc} 2 \mathrm{~b}^{\mathrm{lox} /-}$ and $\mathrm{Atm}^{-/-}$mice. Cells were mock treated or irradiated ( $12 \mathrm{~Gy}, 1 \mathrm{~h}$ recovery).

tions in IR-induced phosphorylation of Atm, Chk1 (a substrate of Atr) or p53 in the absence of $O b f c 2 b$ (Figure 5C; Supplementary Figure 6C). Similar results were also obtained with $O b f c 2 b^{-1-}$ primary murine embryonic fibroblasts (MEFs; Supplementary Figure $6 \mathrm{D}$ and E). Thus, $O b f_{c} 2 b$ is dispensable for Atm/Atr activation and the initiation of DNA damage checkpoints in primary B lymphocytes and embryonic fibroblasts.

\section{Increased Obfc2a expression in Obfc2b-deficient cells}

Obfc2b (orthologue to hSSB1) is homologous with Obfc2a (orthologue to hSSB2) and previous studies have suggested that the two may have overlapping functions (Huang et al, 2009; Li et al, 2009). To determine whether Obfc2a might compensate for $O b f c 2 b$ loss, we analysed Obfc2a protein levels in tissues of $O b f c 2 b^{-1-}$ embryos (Figure 6A). Western blotting showed that $O b f_{c} 2 b$ deficiency results in

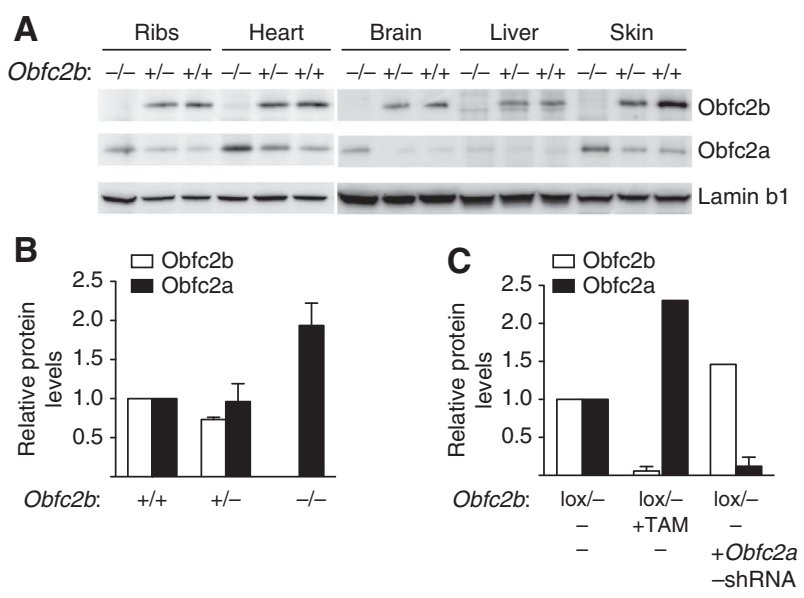

Figure $\mathbf{6}$ Loss of $O b f c 2 b$ increases expression of Obfc2a. (A) Increased Obfc2a protein levels in $O b f c 2 b^{-1-}$ embryos. Western blot for Obfc2a, Obfc2b and Lamin b1 on tissues isolated from E18.5 embryos genotyped as $O b f_{c} 2 b^{-1-}, O b f_{c} 2 b^{+1-}$ and $O b f c 2 b^{+1+}$. (B) Bar diagram shows relative protein levels of Obfc $2 \mathrm{~b}$ and Obfc $2 \mathrm{a}$ detected in five different tissues from wild-type, $O b f c 2 b^{+/-}$and $O b f c 2 b^{-1-}$ mice measured by western blot normalized to Lamin b1. (C) Increased Obfc2a protein levels in Obfc2b-deficient MEFs. Bar diagram shows the relative protein levels of Obfc $2 b$ and Obfc $2 a$ in primary $O b f c 2 b^{\text {lox } /-} ;$ Cre-ERT2 MEFs treated with $5 \mu \mathrm{M}$ Tamoxifen (TAM) for $48 \mathrm{~h}$ or infected with Obfc $2 a$-shRNA expressing lentivirus.

increased Obfc2a protein in all tissues tested (Figure 6A and B). Similar results were obtained by deleting $O b f_{c} 2 b$ in $O b f c 2 b^{\text {lox } /-}$ primary MEFs carrying a Tamoxifen (TAM) inducible Cre transgene (Obfc2b $b^{\text {lox/- }} ;$ Cre-ERT2, Figure 6C). In contrast, RNAi-mediated depletion of Obfc2a in primary MEFs resulted in only small changes in Obfc2b levels (Figure 6C). We conclude that Obfc2a protein levels are increased in cells deficient for $\mathrm{Obfc} 2 b$.

\section{Obfc2a is essential for genomic integrity in proliferating MEFs}

$O b f c 2 b$ deficiency does not significantly affect the recognition or repair of DNA damage in B cells, or the initiation of DNA damage checkpoints in B cells and MEFs (see Figures 4 and 5). To determine whether the compensatory increase in expression of Obfc2a protein (see Figure 6) masks a defect in these processes, we knocked down Obfc2a by RNAi in $O b f c 2 b$-deficient MEFs. To circumvent elevated levels of Obfc2a protein in $O b f c 2 b$-deficient cells, we first knocked down Obfc2a by RNAi in Obfc $2 b^{\text {lox/- }}$; Cre-ERT2 MEFs and subsequently deleted $O b f c 2 b$ using Tamoxifen (Figure 7A).

Knockdown of Obfc2a in primary and SV40 transformed MEFs resulted in increased accumulation of $\gamma \mathrm{H} 2 \mathrm{ax}$ as shown by western blotting (Figure 7B; Supplementary Figure 7A) and in an increase in genomic aberrations (Figure 7C). Further, Obfc2a-shRNA expressing MEFs failed to expand in culture (Figure 7D). In contrast, Tamoxifen induced deletion of $\mathrm{Obfc} 2 b$ did not result in $\gamma \mathrm{H} 2 \mathrm{ax}$ accumulation (Figure 7B; Supplementary Figure 7A), and had only minor effects on proliferation (Figure 7D). Combined depletion of Obfc2b and Obfc2a did not exacerbate the effects of Obfc2a depletion significantly (Figure 7B and D; Supplementary Figure 7A). We conclude that Obfc2a is essential for normal replication and maintenance of genomic stability. 
A

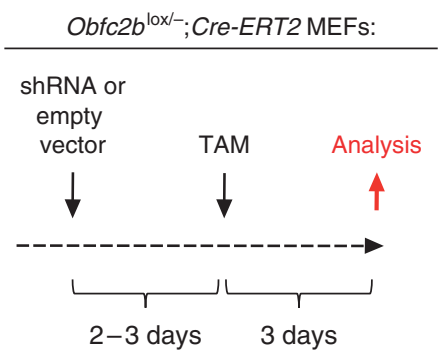

C

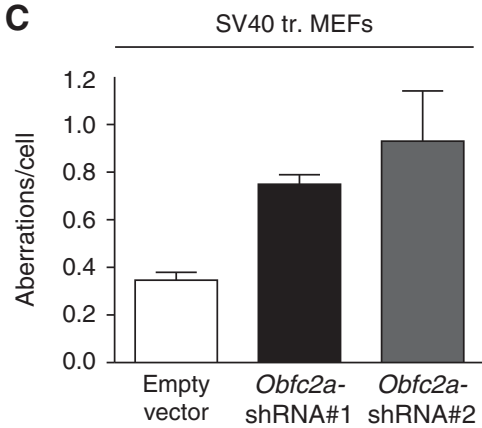

E SV40 tr. Obfc2 $2 b^{\mid 0 x-}$; Cre-ERT2 MEFs

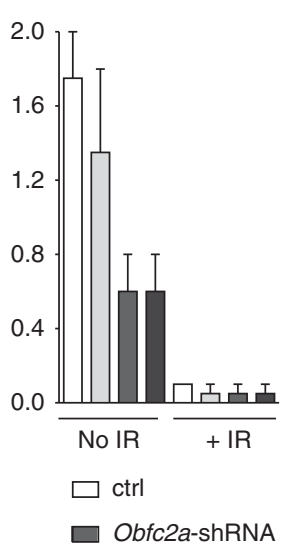

B

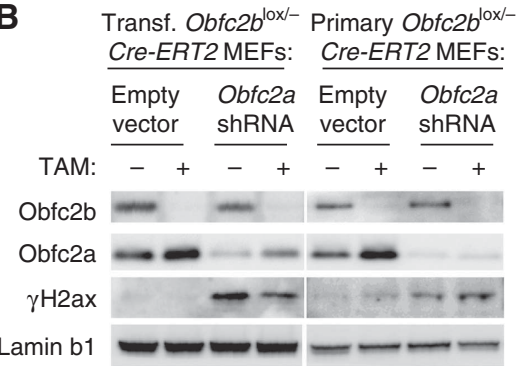

D

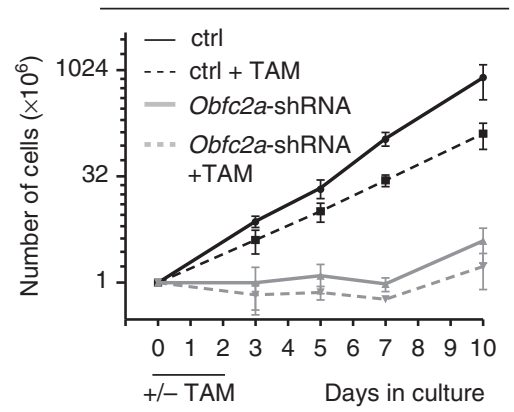

$\mathbf{F}$
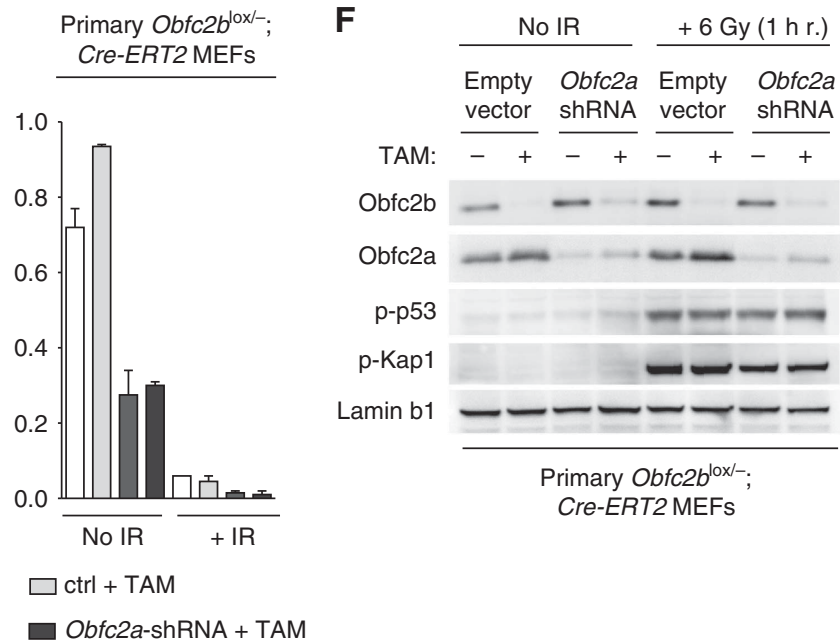

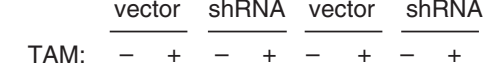

Obfc2b

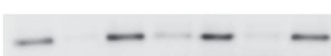

Obfc2a

$$
\text { p-p53 }
$$

p-Kap1

Lamin b1

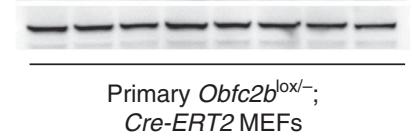

Figure 7 Combined loss of Obfc2b and Obfc2a. (A) Schematic diagram of the sequential knockdown of Obfc2b and Obfc2a in MEFs: Obfc2b ${ }^{\text {lox } /-}$; Cre-ERT2 MEFs were double infected with lentivirus harbouring either empty vector (control) or Obfc2a-shRNA expression vectors. Two to three days after first infection, cells were treated with $5 \mu \mathrm{M}$ Tamoxifen (TAM) for $48 \mathrm{~h}$. Analysis was performed 5-6 days after the first infection. (B) Obfc2a depletion in MEFs results in $\gamma \mathrm{H} 2$ ax accumulation. Western blot of SV40-transformed or primary Obfc2 $b^{\text {lox/- }}$;Cre-ERT2 MEFs treated as indicated for Obfc2b, Obfc2a, $\gamma \mathrm{H} 2 \mathrm{ax}$ and Lamin b1. (C) Obfc2a depletion in MEFs results in increased genomic instability. Analysis of metaphase spreads from SV40-transformed MEFs for genomic aberrations 3 days post infection with Obfc2a-shRNAs or control vector. 30-50 metaphases have been analysed for each group of infection. The graph represents two independent experiments. (D) Obfc2a depletion in MEFs impairs proliferation. Proliferation of SV40-transformed Obfc2 $b^{\text {Oox } /-}$;Cre-ERT2 MEFs treated as indicated and as described in (A). Diagram represents the mean of two independent experiments. Cell numbers were determined by cell counting. (E) Normal G2/M checkpoint in Obfc2a and Obfc2a/Obfc2b double deficient MEFs. Bar diagrams show the summary of experiments analysing histone 3 phosphorylation in $O b f c 2 b^{\text {lox } /}$ ${ }^{-}$;Cre-ERT2 MEFs by flow cytometry. MEFs were treated as in described in (A). Cells were irradiated with 6 Gy and analysed $1 \mathrm{~h}$ post irradiation. Obfc2b and Obfc2a knockdown was verified by western blot in each experiment. (F) Normal IR-induced phosphorylations in Obfc2a and Obfc2a/Obfc2b double deficient MEFs. Western blot of primary Obfc2b $b^{\text {lox } /-}$;Cre-ERT2 MEFs after sequential knockdown of Obfc2a and Obfc2b as described in (A) for Obfc2b, Obfc2a, phosphorylated p53 (serine 15), phosphorylated Kap1 (serine 824) and Lamin b1. Cells were mock treated or irradiated as indicated.

\section{Obfc2a is dispensable for the DNA damage response to irradiation in MEFs}

To examine the effect of Obfc2a deficiency and Obfc2a/Obfc2b double deficiency on the induction of the DNA damage response upon irradiation (IR), we measured IR-induced abrogation of histone 3 phosphorylation by flow cytometry (Figure 7E; Supplementary Figure 7B and C) and IR-induced phospho- rylation of p53, Chk1 and Kap1 by western blot (Figure 7F; Supplementary Figure 7A). In contrast to deletion of $O b f c 2 b$, depletion of Obfc2a resulted in a strong decrease in histone 3 phosphorylation in unirradiated cells (Figure 7E; Supplementary Figure 7B), which was not exacerbated in double deficient cells. This result is in agreement with the proliferation defect observed for Obfc2a-depleted cells. Following 
irradiation, Obfc2a-depleted cells showed a similar reduction in phosphorylated histone 3 as $O b f c 2 b$-deficient or control cells (Figure 7E; Supplementary Figure 7B and C), and therefore the irradiation-induced $\mathrm{G} 2 / \mathrm{M}$ checkpoint appears to be normal in the absence of Obfc2a. Even Obfc2b/Obfc2a double deficient cells efficiently abrogated histone 3 phosphorylation in response to IR. Analysis of irradiation-induced p53, Chk1 and Kap1 phosphorylation by western blot further indicated a normal DNA damage response in the absence of Obfc2a or both, Obfc2a and Obfc2b (Figure 7F; Supplementary Figure 7A). Lower levels of Chk1 phosphorylation in irradiated Obfc2a-depleted cells (Supplementary Figure 7A) correspond to reduced proliferation at the day of analysis (day 5 post infection). This effect is absent at earlier time points after Obfc2a depletion when cells are still proliferating (Supplementary Figure 7D). We conclude that even the combined loss of Obfc2b and Obfc2a does not abrogate the initiation of the DNA damage response in response to irradiation.

\section{Discussion}

Previous reports suggested a fundamental role for hSSB1, the protein product of $O B F C 2 B$, in the recognition and repair of DNA damage (Richard et al, 2008, 2011a, b; Huang et al, 2009; Li et al, 2009; Skaar et al, 2009; Zhang et al, 2009; Xu et al, 2011). Based on RNAi knockdown experiments in human tumour cell lines and neonatal foreskin fibroblasts, hSSB1 was proposed to regulate DNA damage mediated cell-cycle checkpoints and radiosensitivity by binding to DNA breaks, recruiting MRN and activating ATM.

In experiments with mice that carry a null mutation in $O b f c 2 b$ we find no evidence to support the idea that this gene is required for the DNA damage response to irradiation, the activation of Atm or the maintenance of genomic integrity in primary B cells or MEFs. Further, the deficiency of its homologue Obfc2a (orthologue to hSSB2) or combined deficiency of Obfc2b and Obfc2a does not affect the DNA damage response to irradiation.

However, $O b f c 2 b$ seems to play an essential role during embryogenesis. $O b f c 2 b^{-1-}$ mice exhibit growth delay and severe skeletal defects in the skull, limbs and the rib cage. The latter is likely to result in respiratory failure and cause perinatal death of $O b f c 2 b^{-1-}$ embryos. These abnormalities correlate with specific expression of $O b f_{c} 2 b$ in tissues that contribute to bone formation in the embryo and are associated with increased apoptosis at E12.5 in the absence of $O b f c 2 b$. Apoptosis is in turn associated with accumulation of $\gamma \mathrm{H} 2 \mathrm{ax}$, suggesting that DNA damage triggers the apoptosis. Consistent with apoptotic cell death as a mechanism for the skeletal abnormalities, we find that many of these defects can be partially rescued by additional loss of $p 53$.

Persistence of some developmental defects in $\mathrm{Obfc} 2 b^{-/-}$; $p 53^{-1-}$ embryos further suggests that $O b f c 2 b$ deficiency can also interfere with normal cellular function beyond the induction of p53-mediated apoptosis during the development of skeletal structures. Since we show that the $O b f c 2 b$ homologue $O b f c 2 a$ is essential for proliferation in MEFs and Obfc2b and Obfc2a appear to have overlapping functions, it is possible that skeletal defects that are not mediated by $p 53$ arise as a consequence of an altered proliferation capacity in cells that specifically require $O b f_{c} 2 b$.

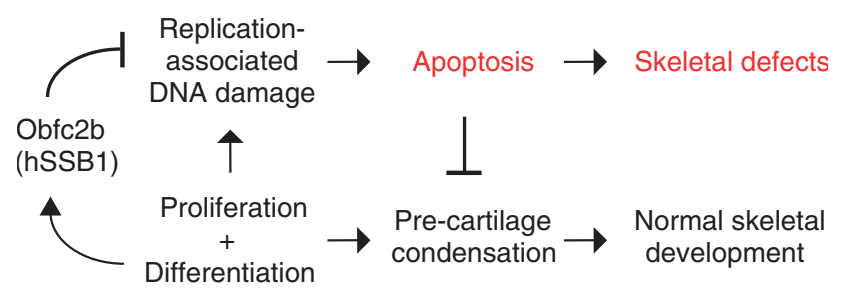

Figure 8 Obfc $2 b$ supports normal skeletogenesis by suppressing replication-associated DNA damage. Model of $O b f_{c} 2 b$ function during embryogenesis. During the development of pre-cartilage mesenchymal condensation at E12.5 the single-stranded DNA-binding protein Obfc 2 b prevents replication-associated DNA damage. In the absence of Obfc2b such DNA damage results in increased apoptosis, which interferes with pre-cartilage condensations. As a consequence, $O b f c 2 b^{-/-}$embryos develop skeletal defects.

Increased DNA damage and apoptosis in $O b f c 2 b^{-/-}$ embryos is associated with defective pre-cartilage mesenchymal condensation. Apoptosis has been shown to occur before the onset of mesenchymal condensation in many mouse models with skeletal defects (Akiyama et al, 2002; Guha et al, 2002; Cheung et al, 2005; Li et al, 2005; Shim et al, 2010), and it is likely to prevent condensation. Conversely, expression of the transcription factor Sox9 has been suggested to favour bone formation by suppressing apoptosis during mesenchymal condensation (Akiyama et al, 2002). We propose that $O b f c 2 b$ supports the development of normal skeletal structures by preventing apoptosis arising from replicationassociated DNA damage during embryogenesis (Figure 8). $O b f c 2 b$ may do so by protecting ssDNA during replication, which is particularly prone to DNA damage.

Skeletal defects that arise as a consequence of increased genomic instability are not uncommon among human genetic disorders. For example, the Cockayne Syndrome (CS) results from defects in transcription-coupled repair during repair of DNA damage by the nucleotide-excision repair pathway (Venema et al, 1990; de Boer and Hoeijmakers, 2000). Besides increased genomic instability, patients suffering from CS exhibit defects in their extremities, the spine and the skull (de Boer and Hoeijmakers, 2000). Similarly, patients suffering from Fanconi Anaemia (FA) or Seckel Syndrome exhibit increased genomic instability and skeletal abnormalities (McKusick et al, 1967; Chaganti and Houldsworth, 1991) and reviewed in Kerzendorfer and O’Driscoll (2009). In mice, only the Seckel Syndrome-related mutation leads to skeletal abnormalities (Murga et al, 2009) while CS and FA mutations do not. Seckel mice exhibit improper alternative splicing of the Atr gene and, as a consequence, Seckel mice express less Atr protein, leading to increased replicative stress and increased apoptosis (Murga et al, 2009). Similarly to the human disorder, Seckel mice exhibit skeletal defects in the skull. Together, the Seckel and $O b f c 2 b^{-/-}$ mouse models suggest that replication-associated DNA damage and apoptosis are a significant cause for skeletal malformations.

The best-characterized ssDNA-binding protein in eukaryotes is replication protein A (RPA). RPA is primarily recruited to ssDNA lesions that are exposed in collapsed replication forks or resected dsDNA breaks during the $\mathrm{S}$ phase of the cell-cycle. RPA recruits ATR and the HR machinery to these lesions (Zou and Elledge, 2003). As might be expected, Rpal mutation in mice predominantly affects 
proliferation and the maintenance of genome integrity (Wang et al, 2005). In contrast, we show that the ssDNA binding protein Obfc2b is not required for proliferation of $B$ lymphocytes or MEFs. However, this analysis is complicated by the finding that Obfc2b (hSSB1) depletion leads to a compensatory increase in protein of its homologue Obfc2a (hSSB2), which forms similar heterotrimeric ssDNA-binding complexes as Obfc2b (Huang et al, 2009; Li et al, 2009; Skaar et al, 2009; Zhang et al, 2009). Furthermore, depletion of Obfc2a resulted in a severe impairment in proliferation, $\gamma \mathrm{H} 2 \mathrm{ax}$ accumulation and an increase in genomic aberrations. Therefore, Obfc2b/Obfc2a proteins (hSSB1/hSSB2) may share common functional characteristics with Rpa1 including a requirement for these factors in cell division. However, their requirement appears to be cell type specific.

In agreement with previous studies we find that deficiency of Obfc2b (hSSB1) or Obfc2a (hSSB2) results in genomic instability and in a reduction in phosphorylated histone 3 (Richard et al, 2008; Zhang et al, 2009). Moreover deletion of $O b f c 2 b$ results in a compensatory increase in Obfc2a protein (Huang et al, 2009). However, hSSB1 has also been reported to control the G1/S and G2/M DNA damage checkpoints, ATM activation, and the repair of DNA damage by NHEJ and HR (Richard et al, 2008; Huang et al, 2009). None of these is altered by $O b f_{c} 2 b$ deletion in mice, or by Obfc2a knockdown in our experiments. However, our work differs from previous experiments in that the latter were performed using continuously growing cell lines, which may have acquired defective DNA damage responses while undergoing transformation (e.g., Broceno et al, 2002). We speculate that such additional abnormalities made the cultured cells more prone to show defects in cell-cycle checkpoints or the DNA damage response after depletion of hSSB1.

In summary, we report an essential, unique and cell type-specific role of the $h S S B 1$ orthologue $O b f c 2 b$ during embryogenesis. Loss of $O b f c 2 b$ results in apoptosis of cell lineages that are essential for skeletal development and depend on $O b f c 2 b$. Moreover, $O b f c 2 b$ and its homologue Obfc2a (orthologue to $h S S B 2$ ) appear to be co-regulated in that loss of $O b f c 2 b$ leads to a compensatory increase in Obfc2a protein. These ssDNA-binding proteins are not required to initiate the DNA damage response to irradiation, but together play an important role in normal cellular proliferation and the suppression of replication-associated DNA damage. Proliferation defects and replication-associated DNA damage are likely to result in apoptosis in rapidly dividing cells as observed during early embryogenesis in select domains of $O b f c 2 b^{-1-}$ embryos.

\section{Materials and methods}

\section{Mice}

$O b f c 2 b^{\text {lox } /+}$ mice were produced by HR in C57BL/6 albino ES cells. Details on the targeting vector, screening by Southern blot, and genotyping PCR are provided in the legends to the Supplementary Figures. FLPe (a gift by Dr Susan Dymecki; Rodriguez et al, 2000), EIIA $^{\text {Cre }}$ (Lakso et al, 1996), CD19 Cre (Rickert et al, 1997), Cre-ERT2 (de Luca et al, 2005), Atm ${ }^{-1-}$ (Barlow et al, 1996), and $p 53^{-1-}$ mice (Jacks et al, 1994) were used for breeding with $O b f c 2 b^{\mathrm{NEO}-l o x /+}$, $O b f c 2 b^{\text {lox } /+}$ or $O b f c 2 b^{+/-}$mice as indicated. All experiments were in agreement with protocols approved by the Rockefeller University and National Institutes of Health (NIH) Institutional Animal Care and Use Committee.

\section{Fetal liver transfer}

Fetal liver transfers were performed with SJL mice as hosts (The Jackson Laboratory) as described in Horwitz et al (1997), with the exception that mice were irradiated with a dose of $2 \times 500$ rad with a 3-h recovery between each irradiation and before injection.

\section{MEF culture and shRNA infection}

Primary MEFs were isolated from E12.5 embryos and frozen as aliquots at passage 2 (1 week). Immortalized MEFs were generated by infection with SV40 large T retrovirus at 2 weeks of cell culture. Viral supernatant was generated as described in Robbiani et al (2008). Lentiviral supernatant was produced by transfection of 293T cells with $\Delta 8.9$ and VSV encoding helper plasmids (Naldini et al, 1996) and either empty vector (pLKO-IRES-GFP; Open Biosystems) or Obfc2a-shRNA encoding expression vectors (TRCN0000177652 [sh1], TRCN0000178020 [sh2]; Open Biosystems). 4-Hydroxytamoxifen (TAM) was from Sigma.

\section{Tissue sections and TUNEL analysis}

Frozen tissue sections were prepared from E10.5 and E12.5 embryos as described (Lindquist et al, 2004). Tissue sections from E16.5 embryos were prepared by paraffin embedding and further sectioning by the Laboratory of Comparative Pathology (Rockefeller University). TUNEL of tissue sections was performed using the In Situ Cell Death Detection Kit, TMR red (Roche).

\section{B cell cultures}

Primary B cells were isolated from spleen and treated as described (Bothmer et al, 2010). B cells were kept in culture with $25 \mu \mathrm{g} / \mathrm{ml}$ lipopolysaccharide (LPS) (Sigma) and $5 \mathrm{ng} / \mathrm{ml}$ of mouse recombinant interleukin 4 (IL-4) (Sigma) for 4 days and percentage of immunoglobulin (Ig) switching was measured by flow cytometry. If indicated, $0.5 \mu \mathrm{g} / \mathrm{ml} \mathrm{RP} 105$ (RP/14, BD) was added to the culture medium. Irradiation was performed after $48 \mathrm{~h}$ of culture using the dosages and recovery times indicated. CFSE (Molecular Probes) labelling for proliferation analysis was performed as described in Bothmer et al (2010). PARP inhibitor (PARPi, Ku58948) and ATM inhibitor (ATMi, Ku55933) were from KuDOS and used at a concentration of 1 and $2.5 \mu \mathrm{M}$, respectively.

\section{DNA damage checkpoint analysis}

For the analysis of $\mathrm{G} 2 / \mathrm{M}$ arrest, irradiated or mock-treated cells were stained using an anti-phosphorylated histone 3 (serine 10, clone D2C8) antibody (Cell Signaling) according to manufacturer's instructions. For the analysis of G1/S arrest, the APC-BrdU flow kit was used (BD). B cells were irradiated at $48 \mathrm{~h}$ of culture with LPS and IL- 4 and harvested at time points indicated.

\section{Western blot}

Western blot was performed as described in Feldhahn et al (2005). The following antibodies were used: Anti-phospho-Histone H2a.X (serine 139) clone JBW301 (Millipore), anti-phospho-Atm (serine 1981) (Rockland), anti-phospho-Chk1 (serine 317) (R\&D), antiphospho-p53 (serine 15) (Cell Signaling), anti- $\alpha$ Tubulin (Abcam), anti-Lamin b1 (Abcam), anti-hSSB1 (Bethyl Laboratories), antiObfc2a (Proteintech Group) and anti-phospho-Kap1 (serine 824) (Bethyl Laboratories).

\section{Flow cytometry}

Single cell suspensions from bone marrow, spleen or thymus were obtained as described (Robbiani et al, 2008) and stained using the following antibodies: B220-PE, B220-APC, B220-PerCPcy5, Cd19-APC, IgM-PE, IgD-FITC, Cd3-PE, Cd8-PE, Cd4-FITC, Cd42.2PerCPcy5, TCR $\gamma / \delta$-PE, TCR $\alpha / \beta$-FITC (BD). For analysis of CSR, an anti-IgG1-APC antibody (BD) or an anti-IgG3-biotin antibody (Southern Biotech) in combination with Steptavidin-APC (BD) was used.

\section{Metaphase spreads analysis}

Metaphase spreads were prepared and imaged as described (Callen et al, 2007). B cells were incubated for $1 \mathrm{~h}$ with $0.1 \mu \mathrm{g} / \mathrm{ml}$ Colcemid (Roche) before metaphase preparation; MEFs were incubated for $3 \mathrm{~h}$ with Colcemid. 


\section{c-myc/lgh translocation analysis}

PCR analysis of $c-m y c / I g h$ translocations was performed as described in Robbiani et al (2008). In brief, genomic DNA (gDNA) from B cells stimulated with $25 \mu \mathrm{g} / \mathrm{ml}$ LPS (Sigma) and $5 \mathrm{ng} / \mathrm{ml}$ mouse recombinant IL-4 (Sigma) for 4 days was extracted, and 500 ng gDNA (equivalent of 100000 cells) was used in each PCR. After gel electrophoresis of PCR products, agarose gels were subjected to Southern blotting. Bands detected by both a c-myc and an Igh probe were scored as translocation.

\section{Skeletal preparations}

Skeletal preparations and staining with Alcian blue (Sigma) and Alizarin red (Sigma) to visualize cartilage and bone/mineralized tissue was performed on day E18.5 p.c. or P0 embryos as indicated according to McLeod (1980), Selleri et al (2001) and Ferretti et al (2011).

\section{Micro-computer tomography}

P0 embryos were formalin embedded and subjected to MicroCT. In all, $3.5 \mu \mathrm{m}$ voxel size, $45 \mathrm{KVp}, 0.36$ degrees rotation step, 180 degrees angular range, $400 \mathrm{~ms}$ exposure and 1 averaged frame per view were used for the scans, which were performed in air. The Scanco $\mu \mathrm{CT}$ software (HP, DECwindows Motif 1.6) was used for 3D reconstruction, evaluation and viewing of images. After $3 \mathrm{D}$ reconstruction, the volumes of interest were segmented and analysed using a global threshold of $0.3 \mathrm{~g} / \mathrm{ccm}$. Directly measured bone volume fraction (BV/TV) and tissue mineral density (TMD) were calculated for mid-diaphysis for estimating the differences between $O b f c 2 b^{+1+}$ and $O b f c 2 b^{-1-}$ embryos.

\section{In situ hybridization}

Whole-mount in situ hybridization on E10.5 and E12.5 embryos and probe purification was performed as described (Ferretti et al, 2011, Selleri et al, 2001). Murine $O b f c 2 b$ mRNA-specific sense and antisense probes were produced by PCR amplification of the last exon and $3^{\prime} \mathrm{UTR}$ of $\mathrm{Obfc2b}$ using $5^{\prime}$-TTCCGAGAACCAGAACGG-3' as forward and $5^{\prime}$-AAGGAGGGCAGGCAGAGG- $3^{\prime}$ as reverse primer on cDNA from wild-type B cells. The PCR product was ligated into the pCR4-TOPO vector (Invitrogen) and the plasmid sequenced and linearized using PmeI (NEB) or NotI (NEB). Sox9 probes were produced using a Sox9 cDNA encoding plasmid (Wright et al, 1995). Digoxigenin (DIG)-labelled sense and anti-sense probes were produced by in vitro transcription using $\mathrm{T} 3$ and $\mathrm{T} 7$ primers and the DIG RNA labeling kit (Roche).

\section{Isolation of chondrocytes, osteoblasts and osteoclasts and gene array analysis}

Primary chondrocytes were isolated from the sternum of E18.5 p.c. old mice by pronase and collagenase treatment as described in
Lefebvre et al (1994) and Retting et al (2009). After expanding for 7 days in cell culture, chondrocytes were harvested by trypsination. Primary osteoblasts were isolated from E18.5 p.c. old mice from the part of the calvaria of the skull that has been identified in the skeletal preparations to be already mineralized (Alizarin Red staining, see Figure 2B). Calvaria plates were then pre-digested twice by $0.1 \mathrm{mg} / \mathrm{ml}$ collagenase in aMEM medium at $37^{\circ} \mathrm{C}$ for $15 \mathrm{~min}$. Bone plates were then cultured in aMEM medium (Invitrogen) $+10 \%$ fetal calf serum $+1 \%$ Penicillin/Streptomycin (Invitrogen) for 13 days and outgrowing osteoblasts were harvested by trypsination. Osteoclasts were isolated by culturing erythrocytedepleted bone marrow cells from the femur in $\alpha$ MEM medium $+10 \%$ fetal calf serum $+1 \%$ Penicillin/Streptomycin including $20 \mathrm{ng} / \mathrm{ml}$ murine M-CSF (PeproTech) for $24 \mathrm{~h}$. Non-adherent cells were transferred to new media containing $30 \mathrm{ng} / \mathrm{ml}$ murine M-CSF and $40 \mathrm{ng} / \mathrm{ml}$ RANK-L (PeproTech) and cultured for 5 more days. Media was replaced by fresh media every 2 days. Multinucleated giant cells were stained by TRAP staining (Sigma-Aldrich) to verify osteoclast identity. RNA was extracted from $2.5 \times 10^{6}$ chondrocytes and osteoblasts, and from one $10 \mathrm{~cm}$ dish for osteoclasts using Trizol (Invitrogen). RNA was subjected to whole genome gene expression analysis using the MouseRef- 8 v2.0 Expression BeadChip (Illumina). Data was analysed using GeneSpring GX software.

\section{Supplementary data}

Supplementary data are available at The EMBO Journal Online (http://www.embojournal.org).

\section{Acknowledgements}

All members of the Nussenzweig laboratory for discussions. Klara Velinzon for cell sorting. The Rockefeller University Gene Targeting Facility for the generation of mutant mice. The work was supported by an NIH grant to MCN (R01 AI037526-18) and an NIH grant to LS (RO1 HD043997). NF was a Fellow of the Leukemia and Lymphoma Society. MCN is a Howard Hughes Medical Institute Investigator.

Author contributions: NF designed and performed most experiments. EF performed skeletal preparations on E18.5 embryos and assisted in in situ hybridizations. DFR assisted in the design of the $O b f c 2 b^{\text {flox }}$ targeting vector. SD helped on metaphase preparations. EC performed the analysis of all prepared metaphase spreads. LS supervised experiments performed on embryos. AN and MCN supervised all experiments. NF and MCN wrote the manuscript.

\section{Conflict of interest}

The authors declare that they have no conflict of interest.

\section{References}

Akiyama H, Chaboissier MC, Martin JF, Schedl A, de Crombrugghe B (2002) The transcription factor Sox9 has essential roles in successive steps of the chondrocyte differentiation pathway and is required for expression of Sox 5 and Sox6. Genes Dev 16: 2813-2828

Barlow C, Hirotsune S, Paylor R, Liyanage M, Eckhaus M, Collins F, Shiloh Y, Crawley JN, Ried T, Tagle D, Wynshaw-Boris A (1996) Atm-deficient mice: a paradigm of ataxia telangiectasia. Cell 86: 159-171

Bothmer A, Robbiani DF, Feldhahn N, Gazumyan A, Nussenzweig A, Nussenzweig MC (2010) 53BP1 regulates DNA resection and the choice between classical and alternative end joining during class switch recombination. J Exp Med 207: 855-865

Broceno C, Wilkie S, Mittnacht S (2002) RB activation defect in tumor cell lines. Proc Natl Acad Sci USA 99: 14200-14205

Bryant HE, Schultz N, Thomas HD, Parker KM, Flower D, Lopez E, Kyle S, Meuth M, Curtin NJ, Helleday T (2005) Specific killing of BRCA2-deficient tumours with inhibitors of poly(ADP-ribose) polymerase. Nature 434: 913-917

Bunting SF, Callen E, Wong N, Chen HT, Polato F, Gunn A, Bothmer A, Feldhahn N, Fernandez-Capetillo O, Cao L, Xu X, Deng CX, Finkel T, Nussenzweig M, Stark JM, Nussenzweig A

(2010) 53BP1 inhibits homologous recombination in Brca1-deficient cells by blocking resection of DNA breaks. Cell 141: 243-254 Callen E, Jankovic M, Difilippantonio S, Daniel JA, Chen HT, Celeste A, Pellegrini M, McBride K, Wangsa D, Bredemeyer AL, Sleckman BP, Ried T, Nussenzweig M, Nussenzweig A (2007) ATM prevents the persistence and propagation of chromosome breaks in lymphocytes. Cell 130: 63-75

Chaganti RS, Houldsworth J (1991) Fanconi anemia: a pleotropic mutation with multiple cellular and developmental abnormalities. Ann Genet 34: 206-211

Cheung M, Chaboissier MC, Mynett A, Hirst E, Schedl A, Briscoe J (2005) The transcriptional control of trunk neural crest induction, survival, and delamination. Dev Cell 8: 179-192

de Boer J, Hoeijmakers JH (2000) Nucleotide excision repair and human syndromes. Carcinogenesis 21: 453-460

de Luca C, Kowalski TJ, Zhang Y, Elmquist JK, Lee C, Kilimann MW, Ludwig T, Liu SM, Chua Jr SC (2005) Complete rescue of obesity, diabetes, and infertility in $\mathrm{db} / \mathrm{db}$ mice by neuron-specific LEPR-B transgenes. J Clin Invest 115: 3484-3493

Dudley DD, Chaudhuri J, Bassing CH, Alt FW (2005) Mechanism and control of $\mathrm{V}(\mathrm{D}) \mathrm{J}$ recombination versus class switch recombination: similarities and differences. Adv Immunol 86: 43-112 
Feldhahn N, Klein F, Mooster JL, Hadweh P, Sprangers M, Wartenberg M, Bekhite MM, Hofmann WK, Herzog S, Jumaa H, Rowley JD, Muschen M (2005) Mimicry of a constitutively active pre-B cell receptor in acute lymphoblastic leukemia cells. $J$ Exp Med 201: 1837-1852

Fernandez-Capetillo O, Chen HT, Celeste A, Ward I, Romanienko PJ, Morales JC, Naka K, Xia Z, Camerini-Otero RD, Motoyama N, Carpenter PB, Bonner WM, Chen J, Nussenzweig A (2002) DNA damage-induced G2-M checkpoint activation by histone H2AX and 53BP1. Nat Cell Biol 4: 993-997

Ferretti E, Li B, Zewdu R, Wells V, Hebert JM, Karner C, Anderson MJ, Williams T, Dixon J, Dixon MJ, Selleri L (2011) A conserved Pbx-Wnt-p63-Irf6 regulatory module controls face morphogenesis by promoting epithelial apoptosis. Dev Cell 21: 627-641

Gao Y, Sun Y, Frank KM, Dikkes P, Fujiwara Y, Seidl KJ, Sekiguchi JM, Rathbun GA, Swat W, Wang J, Bronson RT, Malynn BA, Bryans M, Zhu C, Chaudhuri J, Davidson L, Ferrini R, Stamato T, Orkin SH, Greenberg ME et al (1998) A critical role for DNA end-joining proteins in both lymphogenesis and neurogenesis. Cell 95: 891-902

Guha U, Gomes WA, Kobayashi T, Pestell RG, Kessler JA (2002) In vivo evidence that BMP signaling is necessary for apoptosis in the mouse limb. Dev Biol 249: 108-120

Hall BK, Miyake T (2000) All for one and one for all: condensations and the initiation of skeletal development. Bioessays 22: 138-147

Horwitz BH, Scott ML, Cherry SR, Bronson RT, Baltimore D (1997) Failure of lymphopoiesis after adoptive transfer of NF-kappaBdeficient fetal liver cells. Immunity 6: 765-772

Huang J, Gong Z, Ghosal G, Chen J (2009) SOSS complexes participate in the maintenance of genomic stability. Mol Cell 35: 384-393

Jacks T, Remington L, Williams BO, Schmitt EM, Halachmi S, Bronson RT, Weinberg RA (1994) Tumor spectrum analysis in p53-mutant mice. Curr Biol 4: 1-7

Jackson SP, Bartek J (2009) The DNA-damage response in human biology and disease. Nature 461: 1071-1078

Jankovic M, Nussenzweig A, Nussenzweig MC (2007) Antigen receptor diversification and chromosome translocations. Nat Immunol 8: 801-808

Kerzendorfer C, O’Driscoll M (2009) Human DNA damage response and repair deficiency syndromes: linking genomic instability and cell cycle checkpoint proficiency. DNA Repair (Amst) 8: 1139-1152

Kronenberg HM (2003) Developmental regulation of the growth plate. Nature 423: 332-336

Lakso M, Pichel JG, Gorman JR, Sauer B, Okamoto Y, Lee E, Alt FW, Westphal H (1996) Efficient in vivo manipulation of mouse genomic sequences at the zygote stage. Proc Natl Acad Sci USA 93: $5860-5865$

Lefebvre V, Garofalo S, Zhou G, Metsaranta M, Vuorio E, De Crombrugghe B (1994) Characterization of primary cultures of chondrocytes from type II collagen/beta-galactosidase transgenic mice. Matrix Biol 14: 329-335

Li C, Xu X, Nelson DK, Williams T, Kuehn MR, Deng CX (2005) FGFR1 function at the earliest stages of mouse limb development plays an indispensable role in subsequent autopod morphogenesis. Development 132: 4755-4764

Li Y, Bolderson E, Kumar R, Muniandy PA, Xue Y, Richard DJ, Seidman M, Pandita TK, Khanna KK, Wang W (2009) HSSB1 and hSSB2 form similar multiprotein complexes that participate in DNA damage response. J Biol Chem 284: 23525-23531

Lindquist RL, Shakhar G, Dudziak D, Wardemann H, Eisenreich T, Dustin ML, Nussenzweig MC (2004) Visualizing dendritic cell networks in vivo. Nat Immunol 5: 1243-1250

McKusick VA, Mahloudji M, Abbott MH, Lindenberg R, Kepas D (1967) Seckel's bird-headed dwarfism. N Engl J Med 277: 279-286

McLeod MJ (1980) Differential staining of cartilage and bone in whole mouse fetuses by alcian blue and alizarin red S. Teratology 22: 299-301

Mendez J, Stillman B (2003) Perpetuating the double helix: molecular machines at eukaryotic DNA replication origins. Bioessays 25: $1158-1167$

Murga M, Bunting S, Montana MF, Soria R, Mulero F, Canamero M, Lee Y, McKinnon PJ, Nussenzweig A, Fernandez-Capetillo O (2009) A mouse model of ATR-Seckel shows embryonic replicative stress and accelerated aging. Nat Genet 41: 891-898

Naldini L, Blomer U, Gallay P, Ory D, Mulligan R, Gage FH, Verma IM, Trono D (1996) In vivo gene delivery and stable transduction of nondividing cells by a lentiviral vector. Science 272: $263-267$

Ramiro AR, Jankovic M, Callen E, Difilippantonio S, Chen HT, McBride KM, Eisenreich TR, Chen J, Dickins RA, Lowe SW, Nussenzweig A, Nussenzweig MC (2006) Role of genomic instability and p53 in AID-induced c-myc-Igh translocations. Nature 440: $105-109$

Ramiro AR, Jankovic M, Eisenreich T, Difilippantonio S, Chen-Kiang S, Muramatsu M, Honjo T, Nussenzweig A, Nussenzweig MC (2004) AID is required for c-myc/IgH chromosome translocations in vivo. Cell 118: 431-438

Retting KN, Song B, Yoon BS, Lyons KM (2009) BMP canonical Smad signaling through Smad1 and Smad5 is required for endochondral bone formation. Development 136: 1093-1104

Richard DJ, Bolderson E, Cubeddu L, Wadsworth RI, Savage K, Sharma GG, Nicolette ML, Tsvetanov S, Mcllwraith MJ, Pandita RK, Takeda S, Hay RT, Gautier J, West SC, Paull TT, Pandita TK, White MF, Khanna KK (2008) Single-stranded DNA-binding protein hSSB1 is critical for genomic stability. Nature 453: 677-681

Richard DJ, Cubeddu L, Urquhart AJ, Bain A, Bolderson E, Menon D, White MF, Khanna KK (2011a) hSSB1 interacts directly with the MRN complex stimulating its recruitment to DNA doublestrand breaks and its endo-nuclease activity. Nucleic Acids Res 39: 3643-3651

Richard DJ, Savage K, Bolderson E, Cubeddu L, So S, Ghita M, Chen DJ, White MF, Richard K, Prise KM, Schettino G, Khanna KK (2011b) hSSB1 rapidly binds at the sites of DNA double-strand breaks and is required for the efficient recruitment of the MRN complex. Nucleic Acids Res 39: 1692-1702

Rickert RC, Roes J, Rajewsky K (1997) B lymphocyte-specific, Cremediated mutagenesis in mice. Nucleic Acids Res 25: 1317-1318

Robbiani DF, Bothmer A, Callen E, Reina-San-Martin B, Dorsett Y, Difilippantonio S, Bolland DJ, Chen HT, Corcoran AE, Nussenzweig A, Nussenzweig MC (2008) AID is required for the chromosomal breaks in c-myc that lead to c-myc/IgH translocations. Cell 135: 1028-1038

Rodriguez CI, Buchholz F, Galloway J, Sequerra R, Kasper J, Ayala R, Stewart AF, Dymecki SM (2000) High-efficiency deleter mice show that FLPe is an alternative to Cre-loxP. Nat Genet 25: $139-140$

Rooney S, Chaudhuri J, Alt FW (2004) The role of the non-homologous end-joining pathway in lymphocyte development. Immunol Rev 200: 115-131

Selleri L, Depew MJ, Jacobs Y, Chanda SK, Tsang KY, Cheah KS, Rubenstein JL, O'Gorman S, Cleary ML (2001) Requirement for Pbx1 in skeletal patterning and programming chondrocyte proliferation and differentiation. Development 128: 3543-3557

Shim M, Foley J, Anna C, Mishina Y, Eling T (2010) Embryonic expression of cyclooxygenase-2 causes malformations in axial skeleton. J Biol Chem 285: 16206-16217

Skaar JR, Richard DJ, Saraf A, Toschi A, Bolderson E, Florens L, Washburn MP, Khanna KK, Pagano M (2009) INTS3 controls the hSSB1-mediated DNA damage response. J Cell Biol 187: 25-32

Venema J, Mullenders LH, Natarajan AT, van Zeeland AA, Mayne LV (1990) The genetic defect in Cockayne syndrome is associated with a defect in repair of UV-induced DNA damage in transcriptionally active DNA. Proc Natl Acad Sci USA 87: 4707-4711

Wang Y, Putnam CD, Kane MF, Zhang W, Edelmann L, Russell R, Carrion DV, Chin L, Kucherlapati R, Kolodner RD, Edelmann W (2005) Mutation in Rpa1 results in defective DNA double-strand break repair, chromosomal instability and cancer in mice. Nat Genet 37: 750-755

Wright E, Hargrave MR, Christiansen J, Cooper L, Kun J, Evans T, Gangadharan U, Greenfield A, Koopman P (1995) The Sry-related gene Sox 9 is expressed during chondrogenesis in mouse embryos. Nat Genet 9: 15-20

Xu S, Feng Z, Zhang M, Wu Y, Sang Y, Xu H, Lv X, Hu K, Cao J, Zhang R, Chen L, Liu M, Yun JP, Zeng YX, Kang T (2011) hSSB1 binds and protects p21 from ubiquitin-mediated degradation and positively correlates with p21 in human hepatocellular carcinomas. Oncogene 30: 2219-2229

Zhang F, Wu J, Yu X (2009) Integrator3, a partner of single-stranded DNA-binding protein 1, participates in the DNA damage response. J Biol Chem 284: 30408-30415

Zou L, Elledge SJ (2003) Sensing DNA damage through ATRIP recognition of RPA-ssDNA complexes. Science 300: 1542-1548 